\title{
DOSSIÊ
}

\section{DINAMISMO E CRIATIVIDADE EM ONTOLOGIAS RELIGIOSAS}

\section{DYNAMISM AND CREATIVITY IN RELIGIOUS ONTOLOGIES}

\author{
Martina Ahlert* \\ Ana Stela Cunha** \\ João Leal ${ }^{* * *}$
}

A ideia de território como um "lugar antropológico" passa por uma desconstrução que questiona a centralidade que a categoria sempre teve, tanto nas elaborações metodológicas quanto nas reflexões conceituais (AUGÉ, 2009; APPADURAI, 2007; GUPTA e FERGUSON, 2002). No entanto, uma vez integrado em formulações que o situam em outros níveis de pertencimento, o "lugar/território" ainda parece ser relevante etnográfica e conceitualmente, na medida em que nos fala sobre formas de vida tecidas em contextos específicos. Neste cenário, categorias como tradição e criatividade são constantemente reelaboradas, fazendo o jogo entre percurso histórico e etnografia, fundamental para a compreensão de situações singulares.

Nesse dossiê, propomos pensar essas questões a partir de pesquisas de campo que discutem ontologias múltiplas e religiosidades - pensando em agenciamentos entre pessoas e seres diversos -, que coloquem em diálogo o Brasil, Portugal e o Continente Africano. Justificamos tal escolha pela própria história econômica e social dos dois lados do Atlântico, evidenciando aquilo que Palmié (2007) chamaria de "modernidade atlântica". Essa trata de uma vasta rede de intrincadas relações que

\footnotetext{
* Doutora em Antropologia Social pela Universidade de Brasília. Professora do Departamento de Sociologia e Antropologia (DESOC) e do Programa de Pós-Graduação em Ciências Sociais (PPGCSoc) da Universidade Federal do Maranhão - UFMA (São Luís/MA/BR). E-mail: ahlertmartina@gmail.com.

*** Pós-Doutorada em Antropologia Social pelo ICS e pelo CRIA na Universidade de Lisboa (Lisboa/ PT). Professora Adjunta na Universidade Federal do Maranhão - UFMA (São Bernardo/MA/BR). Pesquisadora do CEI (Centro de Estudos Internacionais, ISCTE, UL). E-MAIL: anastelacunha@gmail.com

**** Professor da Faculdade de Ciências Sociais e Humanas da Universidade Nova de Lisboa NOVA (Lisboa/ PT). E-mail: joao.leal@fcsh.unl.pt.
} 
formam e constroem histórias cá e lá e que produziram - e continuam produzindo um contingente histórico agregado a discursos e práticas locais.

Ao pensarmos os encontros que foram e são produzidos dentro do espaço Atlântico, entendemos que eles se conectam com histórias coloniais particulares que foram mapeadas e se tornaram operativas em manifestações religiosas e culturais na África, na América e na Europa atuais. Reconhecendo vínculos sociais - e as formas e modos com que esses são reconfigurados em termos de "conexões" (AMSELLE, 2001; PALMIÉ, 2002; CUNHA, 2013) e acoplamentos complexos -, propomos pensar sobre territorialidades e pertencimentos (BAYART, 2000) a partir de pesquisas etnográficas.

Nesse sentido, os argumentos e situações apresentados pelas autoras e autores dos textos que compõem o dossiê nos fazem repensar as teorias da cultura e da história do Atlântico ${ }^{1}$; retomam discussões que se tornaram notórias nas literaturas das Ciências Sociais - de missões católicas europeias coloniais às religiões afro-brasileiras, do cristianismo carismático às lutas políticas que mobilizam agências religiosas (FRESTON, 2001; MATORY, 2005; ROUTON, 2006; BLANES e SARRÓ, 2008; CAPONE, 2010). Através delas, os textos enfatizam a possibilidade de traçarmos configurações alternativas que revelam conexões, continuidades e disjunções que emergem nesses cenários.

Tendo esses elementos como vetores, o dossiê nos permite refletir sobre questões como identidade, pessoa, circulação e patrimônio (material e, sobretudo, imaterial), dando especial atenção aos processos de constru- ção de "passados imaginados" e comunidades envolvidas na circulação das práticas "transponíveis" (CSORDAS, 2008). Através das lentes da religiosidade, pensada a partir de suas ancoragens etnográficas, os textos convidam a rever conceitos-chave como o de etnicidade; a imaginar diferentes formas de atuação política para além da questão fundiária; a pensar nas maneiras pelas quais os coletivos interagem com outros grupos e diferentes seres. Quatro artigos o fazem a partir de pesquisas etnográficas assentadas no Maranhão e nos trânsitos que perpassam o estado (os textos de Martina Ahlert, João Leal, Maria da Conceição Salazar Cano e Katerina Chatzikidi); o artigo de Ramon Sarró nos remete ao contexto africano - especificamente a GuinéBissau; e a resenha de Maria do Socorro Rodrigues de Souza Aires, que encerra o conjunto de textos do dossiê, analisa a obra "0 culto do Divino: migrações e transformações" que, por sua vez, conecta Portugal, América do Norte e Brasil.

Os textos se relacionam em aspectos que nos parecem fundamentais à discussão que procuramos mobilizar neste dossiê. 0 primeiro deles remete ao modo como os autores nos colocam perante formas diferenciadas de relacionamento entre pessoas e diferentes tipos de entidades espirituais. Em alguns casos, essas entidades são santos católicos - como Santa Teresa em Itamatatiua (comunidade quilombola na cidade de Alcântara, Maranhão), presente no texto de Katerina Chatzikidi; ou São João e outros santos juninos no caso do bumba meu boi de São Luís, descrito por Maria da Conceição Salazar Cano. Podem envolver o Espírito Santo, mas entre o Espírito Santo invoca-

1. Ver, por exemplo, GILROY, 1993; THORNTON, 1992; PALMIÉ, 2002, 2007; DOORTMONT, 2005; BAILYN E DENAULT, 2008; ANQUANDAH, OPOKU-AGYEMANG e DOORTMONT, 2007; GREENE e MORGAN, 2008; PARÉS e SANSI, 2011. 
do pelos movimentos messiânicos africanos (Ramon Sarró) e o Divino Espírito Santo cultuado nas festas do Divino em São Luís (João Leal e Maria do Socorro Rodrigues de Souza Aires) há, para além de aspectos comuns, diferenças importantes. Finalmente, essas entidades espirituais podem ser encantados, "pessoas que desapareceram sem passar pela experiência de morte, quando foram viver na Encantaria - uma espécie de outro mundo, entre mundo ou diferente dimensão da experiência" -, como sugere Martina Ahlert.

Presentes em plano de relevo no artigo que Ahlert consagra a religiões afro-brasileiras do interior do Maranhão, os encantados surgem também - a par de entidade católicas - no Bumba Meu Boi (Cano) e nas festas do Divino em São Luís (Leal e Aires). Ambos os rituais, ao mesmo tempo que fornecem o contexto para o pagamento de promessas católicas, são uma obrigação para com os encantados. É por essa razão que Cano, no seu artigo sobre o Bumba Meu Boi, discute a adequação de conceitos como sincretismo e crioulização à conceitualização da coexistência - em um mesmo ritual - de dois tipos de entidades espirituais. Essa discussão, como afirma Aires sobre a obra de Leal, poderia ser retomada para o caso das festas do Divino e ainda para o caso do movimento kyangyang de Guiné-Bissau (Sarró).

Confrontando-nos com diferentes tipos de entidades espirituais, os artigos nos colocam também perante modalidades variadas de interlocução entre humanos e não humanos. 0 artigo de Chatzikidi, por exemplo, sublinha a importância de um triângulo constituído por Santa Teresa, as suas terras e seus habitantes. Isso porque as narrativas ouvidas em campo indicam que "a própria Santa os convidou a morar nas suas terras e prometeu cuidá-los. Por meio desse ato, eles se tornaram filhos dela, e prometeram morar lá, cuidar das terras da Santa e reverenciá-la”. A partir disso, o que vale a pena sublinhar é a importância que assume a inter-relação entre a Santa e os quilombolas nos registros - interligados - da propriedade da terra e do idioma do parentesco, na medida em que as pessoas que vivem na comunidade adotaram o sobrenome "de Jesus" como índice direto de sua relação com "Santa Teresa de Jesus".

No artigo de Cano, por sua vez, avulta a diversidade quase barroca de modalidades de promessa associadas ao bumba meu boi:

Há quem promete brincar boi para São João e participar de algum grupo já constituído, ou contratar um grupo para brincar na porta de sua casa, ou oferecer algum bem simbólico e/ou material a determinado grupo, ou "botar um boi" na rua, ou seja, organizar um grupo (...) Tais promessas podem manifestar um caráter temporário podendo ter duração de três, cinco ou sete anos consecutivos, ou um caráter acrônico, uma vez que o promesseiro pode comprometer-se com a brincadeira "enquanto tiver vida" e/ou saúde.

Tanto Sarró como Ahlert, por fim, chamam atenção para a importância de outra forma de interlocução, aquela que passa pela possessão - tanto em religiões afro -brasileiras como em certas formas julgadas mais heterodoxas de cristianismo. Estas últimas, como lembra Sarró, resultam da sua forte ligação à própria tradição cristã dos primeiros tempos que procuram restaurar. Ahlert aponta - com recurso à categoria êmica de "governo" -, para a ampliação dos domínios dos encantados, que oscilam entre a esfera micro dos corpos e objetos dos seus devotos, e a esfera macro da natureza e dos marcos vitais que configuram os territórios. 
As relações entre humanos e não humanos, como evidenciam os artigos, são relações que, ao mesmo tempo em que conectam, são também dotadas de alguma fragilidade, pois podem ser ameaçadas ou mesmo rompidas. Dois exemplos ilustram este ponto. Em Itamatatiua, Chatzikidi mostra como o avanço dos não católicos não só ameaça o vínculo entre a Santa e a terra, como é acompanhado de pressões no sentido da apropriação individualista do território. Em Santa Rosa do Pretos, comunidade mencionada no texto de Ahlert, são os grandes projetos de desenvolvimento que põem em causa as conexões entre os encantados e a geografia espiritual da paisagem. Em um caso e no outro, a subsistência material das pessoas e dos territórios e a subsistência espiritual das entidades se encontram estreitamente articuladas.

Em outros casos, porém, parece haver alguma capacidade de resistência a pressões que em outras circunstâncias poderiam se revelar mais comprometedoras. É o que se passa com rituais cooptados por processos de patrimonialização e/ou de turistificação, como as festas do Divino ou o Bumba Meu Boi. Como Leal demonstra,

A culturalização das festas do Divino abriu certamente uma segunda vida - culturalizada - às festas do Divino de terreiro, mas esta segunda vida não se substituiu à sua primeira vida, isto é, não colocou em causa as principais dimensões [designadamente religiosas] que continua a ser possivel reconhecer nas festas.

É na mesma direção que aponta a contribuição de Conceição Cano sobre o Bumba meu Boi, quando sublinha a continuada importância da promessa e da obrigação em um ritual que é simultaneamente o ex libris patrimonial de São Luís.
Ao pensar a continuidade das relações, rupturas e resistências, os textos remetem a um segundo aspecto em comum: situações etnográficas que trazem processos de transformação. De maneira central, o texto de Sarró problematiza a leitura da ideia de imitação e cópia como processo desinteressante ou desprovido de qualidades analíticas. A partir de seu estudo com os filhos de Nhala - e a forma como desempenham rituais cristãos e muçulmanos -, o autor sugere:

Son copias, sí (tal vez como los ritos de paso, las mascaradas y los sacrificios, que sólo son "auténticos" dentro de un marco hermenéutico que opone lo auténticamente africano a los espurio, pero que en su historicidad interna deben de haberse sometido, en un momento o otro, a dinámicas de copia, como cualquier otra obra humana). Propongo que la copia no sea vista como un resultado, sino una capacidad, una potencia. Sin la potencia humana para copiar ¿habría cultura humana? ¿Sin la capacidad humana de colapsar, e incluso revertir, la historia repitiendo el evento original, habría, realmente, historia?

Sarró compreende a importância de olhar para a imitação (ou para a mimese, nos termos de Levy-Bruhl) como participação e como forma de conexão. Isso porque aqueles que participam do movimento kyangyang, nos momentos de incorporação, oração e glossolalia não repetem ou imitam fórmulas vazias, antes exteriorizam "una vivencia inenarrable”. Pensando ainda no contexto religioso cristão, Chatzikidi analisa o processo de chegada dos "evangélicos" na comunidade de Itamatatiua e os diversos impactos da presença de uma nova igreja no espaço. Seu texto ainda trabalha com um segundo sentido de transformação quando indica as mudanças e 
disputas em torno do conceito de quilombo.

João Leal observa o processo de transformação pelo qual passam as Festas dos Divino nos terreiros de São Luís, em relação às políticas e práticas de patrimonialização. De acordo com o autor, o impacto dessas práticas levou a uma vinculação da Festa com ideias como cultura, raízes e tradição. Essa transformação, entretanto, não surgiu como uma "ressignificação radical das festas (...) mas como um processo de adição de um novo significado - cultural - aos significados - religiosos e sociais - que continuam a caracterizar as festas”. Não se trata, portanto, de uma ressignificação radical, pois uma lógica de abertura se inscrevia previamente nas Festas do Divino, tanto em sua dimensão religiosa (em direção ao catolicismo) quanto social. Dessa forma, “Com a culturalização das festas, essa abertura passou também a fazer-se em direção aos discursos e práticas sobre cultura e patrimônio no Maranhão”. Aires permite compreender as transformações nas festas do Divino, considerando as conexões proporcionadas pelas viagens entre diferentes contextos marcados pela presença portuguesa.

Falar de transformação é também falar sobre determinada gestão do tempo. Nos textos do dossiê são múltiplas as temporalidades evocadas a partir das etnografias. Menciona-se, por exemplo, os calendários cíclicos das festas anuais - seja no contexto das festas juninas protagonizadas pelos grupos de Bumba Meu Boi, seja no calendário dos terreiros, preenchido pelas homenagens aos santos, voduns do tambor de mina e encantados. Chatzikidi, em especial, se dedica a nos apresentar o esforço presente na preparação da festa em homenagem à Santa Teresa na comunidade quilombola de Itamatatiua. Outra forma de pensar as transformações e o tempo remete às concepções êmicas sobre o início das festas ou o começo de determinadas tradições e, neste sentido, não passam incólumes as ponderações sobre, por exemplo, a história da festa do Divino e da festa de Santa Teresa - contada na medida em que se conta a própria história do quilombo.

As transformações nos colocam, ainda, diante de uma discussão sobre criatividade, na medida em que acionam atualizações de determinados fenômenos - como indicam Aires, Leal e Sarró, em seus textos, ao tratarem da passagem do tempo, da manutenção de práticas e da mobilização de novos sentidos nas experiências. Cano nos mostra esse esforço a partir da ideia de "colocar o boi na rua” - princípio que mobiliza mulheres, homens e encantados nas festas de Bumba Meu Boi e que, de modo criativo, funciona como espaço atualizador de práticas sociais. Nesse sentido, Chatzikidi indica claramente a Festa de Santa Teresa como uma reafirmação de vínculos e de distinções importantes entre os moradores de Itamatatiua.

Nos contextos estudados, a criatividade não surge apenas da agência humana, mas também de agências não humanas que participam das situações vividas. Ao narrar conexões traçadas por humanos e não humanos em diferentes domínios da existência, os textos enfatizam a agência e criatividade de pessoas e entidades. Propõem leituras alternativas de fenômenos bastante difundidos - como vemos no esforço de Leal em problematizar a entrada do dinheiro nas festas do Divino Espírito Santo nos terreiros; ou na tentativa, do texto de Sarró em repensar a presença cristã no Continente Africano sob uma ótica que não a da ruptura.

Um terceiro aspecto que conecta os textos do dossiê chama atenção ao fato de que os fenômenos estudados, outrora encapsulados em enquadramentos precisos, 
se espraiam, conectam e redimensionam perspectivas. Nesse sentido, Aires e Leal mostram como as festas do Divino Espírito Santo, estudadas no contexto maranhense, não podem ser compreendidas apenas como entretenimento, na medida em que colocam dimensões culturais, religiosas, políticas e sociais. Cano e Ahlert mostram como os encantados, para além dos rituais propriamente religiosos nas tendas e terreiros, circulam em diferentes espaços - como as festas de Bumba Meu Boi e os enfrentamentos políticos. Chatzikidi indica formas de pensar o território e o pertencimento quilombola que não condizem apenas a questões relacionadas à terra, mas ao pertencimento religioso e a comportamentos a ele associados. Sarró demonstra como a religião compõe um conjunto de elementos utilizados para classificar coletivos em um cenário mais amplo (onde estereótipos são retomados para justificar leituras sobre o pretenso atraso de determinados grupos).

Como os fenômenos analisados não estão circunscritos a domínios específicos, vemos circulação e deslocamento, por exemplo, nos trânsitos entre religião e cultura, entre festa e política, entre tradição e entretenimento. Nesse convite à percepção dos movimentos e transgressões, os autores demonstram como se articulam formas de encontro entre pertencimentos religiosos - quando, por exemplo, santos católicos e entidades de religião afro-brasileira estão associados em uma mesma manifestação (nos textos de Cano e Leal); ou ainda, quando tradições religiosas se cruzam (como descreve Sarró e Leal - de acordo com a resenha de Aires). Nestes casos, nem práticas e nem entidades estão limitadas a domínios (grupos ou mesmo tempos) previamente definidos, mas são mobilizadas em (e mobilizadoras de) experiências vividas pelas pessoas.
Pensando ainda nas conexões, espraiamentos e no questionamento de fronteiras, os textos indicam uma projeção de determinadas práticas para espaços não evidentes, alcançando outras pessoas e outras esferas - como a esfera pública. João Leal, por exemplo, afırma que as Festas do Divino “são a 'festa maior dos terreiros', isto é, a festa que mais abre os terreiros de tambor de mina para fora do seu círculo de frequentadores habituais, conectando-os com redes sociais mais alargadas e projetando-os na esfera pública” (Leal, 2014; 2017) - aspecto comentado ainda por Aires ao analisar sua obra. Chatzikidi, por sua vez, demonstra que uma festa religiosa articula uma cosmopolítica quilombola em relação à posse comunitária da terra. Igualmente, Ahlert pontua sobre a agência dos encantados que, a partir do domínio religioso, informam contextos de discussão política e ambiental.

Ao se basearem em pesquisas etnográficas - e, portanto, nas experiências vividas por mulheres, homens e entidades, os textos falam sobre transformações, disputas e retomadas em torno da mudança e da manutenção do sentido das práticas. Colocar as perspectivas mobilizadas pelas pessoas em diálogo com conceitos e abordagens teóricas é uma das contribuições mais interessantes das etnografias. É com esse intuito que o dossiê se dedica a pensar ideias como território-lugar, etnicidade, criatividade e tradição a partir de situações concretas que marcam formas de existência presentes no contexto Atlântico.

Este dossiê estava sendo finalizado quando Sérgio Ferretti, antropólogo citado em alguns dos artigos, faleceu. É inútil sublinhar o quanto a antropologia das cul- 
turas populares e das religiões afro-brasileiras do Maranhão deve a Sérgio Ferretti. Este dossiê é também uma forma de homenageá-lo.

\section{REFERÊNCIAS}

AMSELLE, J.L. Branchements: Anthropologie de l'universalité des cultures. Paris: Flammarion, 2001.

ANQUANDAH, J. K. OPOKU-AGYEMANG, N. J. DOORTMONT, M. R. (Eds). The Transatlantic Slave Trade: Landmarks, legacies, expectations. Accra: Sub-Saharan Publishers, 2007.

APPADURAI, A. Worship and Conflict under Colonial Rule: a South Indian case. Cambridge University Press, 2007.

AUGÉ, M. Non Places: An introduction to supermodernity. London, New York: Verso, 2009.

BAYART, J. F. Africa in the world: a history of extraversión. Africain Affairs, n. 99, p. 217- 267, 2000.

BAILYN, B.; DENAULT, P. L. (Eds.). Soundings in Atlantic History. Latent Structures and Intellectual Currents, 1500-1830. Cambridge: Cambridge University Press, 2008.

BLANES, R. L.; SARRÓ, R. Introduction. Etnográfica, n. 12, v. 2, p. 371-376, 2008.

CAPONE, S. Searching for Africa in Brazil: Power and tradition in Candomblé. Durham: Duke University Press, 2010.

CSORDAS, T. J. Corpo, significado, cura. Porto Alegre: Editora da UFRGS, 2008.

CUNHA, A. S. João da Mata family: a Pajé materiality. In: ESPÍRITO-SANTO D.; BLANES, R. (Orgs). The Social Life of the Spirits. Chicago: Chicago University Press, 2013. p. 123-158.

DOORTMONT, M. R. The Pen-Pictures of Modern African and African Celebrities by Charles Francis Hutchison: A collective biography of elite society in the Gold Coast Colony. Leiden: Brill, 2005.
FERGUSON, J. The cultural topography of wealth: commodity paths and the structure of property in rural Lesotho. American Anthropologist, n. 94, v. 1, p. 55-73, 1992.

FRESTON, P. Evangelicals and Politics in Asia, Africa and Latin America. Cambridge: Cambridge University Press, 2001.

GILROY, P. The Black Atlantic: Modernity and double consciousness. London: Verso, 1993.

GREENE, J. P.; MORGAN, P. D. (Eds.). Atlantic History: A critical appraisal. Oxford: Oxford University Press, 2009.

GUPTA, A.; FERGUSON, J. Spatializing States: Toward an ethnography of neoliberal governmentality. American Ethnologist, v. 29, issue 4, p. 9811002, 2002.

LEAL, J. A festa maior dos terreiros: Divino e Mina em São Luís (Maranhão). Revista Pós Ciências Sociais, n. 21, p. 105-125, 2014.

. 0 Culto do Divino: migrações e transformações. Lisboa: Edições 70. 2017.

MATORY, J. Black Atlantic Religion: Tradition, transnationalism and matriarchy in afro- brazilian candomblé. Princeton: Princeton University Pres, 2005.

PALMIÉ, S. Wizards and Scientists: Explorations in afro-cuban modernity and tradition. Durham: Duke University Press, 2002. Introduction. Out of Africa? Journal of Religion in Africa, n. 37, v. 2, p. 159-173, 2007.

PARÉS, L. N.; SANSI, R. (Eds.). Sorcery in the Black Atlantic. Chicago: University of Chicago Press, .2011.

ROUTON, K. Trance-nationalism: religious imaginaries of belonging in the black Atlantic. Identities, n. 13, p. 483-502, 2006.

THORNTON, J. Africa and the Africans in the Making of the Atlantic World, 1400-1680. Cambridge: Cambridge University Press, 1992. 
